\title{
Disease-modifying effects of neural regeneration peptide 2945 in the GAERS model of absence epilepsy.
}

Gabi Dezsi ${ }^{1}$, Frank Sieg ${ }^{2}$, Mark Thomas ${ }^{2}$, Terence J O’Brien ${ }^{1}$, Marieke van der Hart $^{3}$, Nigel C Jones ${ }^{1 *}$

${ }^{1}$ Department of Medicine (Royal Melbourne Hospital), University of Melbourne, Melbourne Brain Centre, Parkville, Victoria, Australia, ${ }^{2}$ CuroNZ Ltd, Ruakura Research Centre, 10 Bisley Road, Hamilton 3214, New Zealand, ${ }^{3}$ Brains On-Line, South San Francisco, CA, USA.

*Author for correspondence:

Nigel C Jones, PhD

Department of Medicine (Royal Melbourne Hospital), University of Melbourne, Melbourne Brain Centre, Parkville, Australia, 3052. Ph: +6139035 6402; Fax: +61 393471863.

Email: ncjones@unimelb.edu.au

\section{Keywords:}

Seizures, absence epilepsy, brain, neural regeneration peptide2945, GAERS, disease modification 


\begin{abstract}
Epilepsy is a common neurological condition characterised by spontaneous recurrent seizures. Current anti-epileptic drugs (AEDs) are only effective and tolerated in $\sim 70 \%$ of patients, leaving a substantial proportion of patients untreated. As such, there is a pressing need to develop new therapies. We assessed the anti-seizure activity of Neural Regeneration Peptide 2945 (NRP2945) in the GAERS model of absence epilepsy.

Drug effects on seizures were assessed using two study designs. Male adult GAERS were implanted with EEG electrodes to measure seizure frequency. The first study compared the effects of acute sc injection of vehicle, NRP $10 \mu \mathrm{g} / \mathrm{kg}$, NRP $20 \mu \mathrm{g} / \mathrm{kg}$, and controlled against the active comparator Valproaic acid $(200 \mathrm{mg} / \mathrm{kg})$. In the second study, animals received one of four treatments for four weeks: vehicle, NRP $60 \mu \mathrm{g} / \mathrm{kg} /$ day, NRP $120 \mu \mathrm{g} / \mathrm{kg} /$ day (delivered by continuous infusion) or NRP $20 \mu \mathrm{g} / \mathrm{kg}$ sc injected every second day (e.s.d).

In the acute study, we found significant $(\mathrm{p}<0.01)$ anti-seizure effects in animals treated with NRP2945 $(20 \mu \mathrm{g} / \mathrm{kg})$ and VPA, with NRP2945 slightly more efficacious, despite the 70,000 times lower molar dosage. In the chronic study, animals receiving $120 \mu \mathrm{g} / \mathrm{kg} / \mathrm{day}$ and NRP $20 \mu \mathrm{g} / \mathrm{kg}$ e.s.d had significantly fewer seizures $(\mathrm{p}<0.001)$, compared with vehicle. These effects were sustained for at least 10 days after drug treatment had ceased, indicative of disease-modifying activity.

We demonstrate sustained anti-seizure effects of NRP2945, a potent small molecule peptide which enters the brain and is devoid of adverse effects. Early stage first-in-man trials have been initiated for subcutaneously delivered NRP2945 which is a promising step to providing therapeutic benefits for refractory epilepsy patients.
\end{abstract}




\section{Introduction}

The 'epilepsies' constitute a group of neurological conditions which are collectively characterised by the occurrence of spontaneous and recurrent bursts of hyper-synchronised neuronal firing patterns referred to as seizures. Over the past decades, the number of new anti-epileptic drugs available for treatment of seizures has increased dramatically [1]. However, these new therapies have not appreciably influenced the number of patients unresponsive to treatment, with at least $30 \%$ of patients still experiencing inadequate seizure control with drug therapy [2]. Therefore, there is a pressing need for new and well-tolerated drug therapies for refractory forms of epilepsy, in particular. One avenue for drug development in this regard is to explore alternative strategies for targeted treatments that include synaptic vesicular proteins and the respective targets. For example, Frasca et al. (2011) have shown that extrasynaptic localization of the NMDA receptor subunit NR2B is due to decreased interaction between NR2B and the postsynaptic density-95 (PSD-95) during the process of epileptogenesis [3]. The importance of synaptic vesicular proteins and its significant connection to epilepsy has also has been shown in human patients with maternal allelic deletions within the gene of the human vesicular priming protein CADPS2 responsible for the secretion of NT-3 and BDNF. These mutations lead to intellectual disability and refractory epilepsy in conceived infants [4]. So far, there is no approved or late stage clinical drug candidate that can provide a disease-modifying impact on epileptogenesis.

Over the past decade, there is increasing consensus that inflammatory processes are key mediators in the development and maintenance of the pathophysiology of epilepsy [5]. For example, increased levels of inflammatory lymphocytes and phagocytes as well as proinflammatory mediators are observed in excised brain tissue from patients with medically refractory epilepsy [6,7], and in many animal models of the disease [8]. Moreover, many infectious or autoimmune diseases are associated with seizures [9], and the inflammatory condition Rasmussen's encephalitis represents a severe epileptic encephalopathy with intractable focal seizures [10]. Also, in animal models of epilepsy, strategies to block inflammation reduce the duration and frequency of seizures [11-13]. While there are numerous mediators involved in pro-inflammatory processes, preventing the activation of these inflammatory cascades by simultaneously maintaining a permissive environment for synaptogenesis represents a promising strategy to improve treatment of epilepsy.

Neural Regeneration Peptide, named NRP2945, derives from the human NRP gene

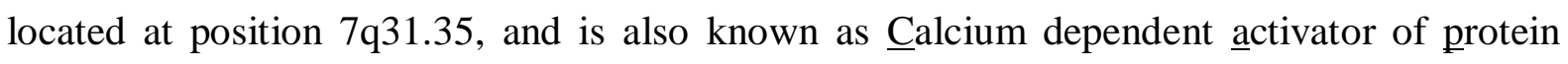
secretion 2 (CAPS-2 synonymous to CADPS2) [14]. NRP2945 represents amino acid 
position 40-50 within the CAPS-2 sequence. NRP2945 is a synthetic 11-mer peptidomimetic with the sequence H-GRRAAPGRAIBGG-NH $\mathrm{NH}_{2}$ that has been chemically modified at position four (alanine switch) and position nine of the amino acid sequence to enhance physicochemical shelf-life stability. For this purpose, alanine has been replaced with the nonnatural amino acid $\alpha$-aminoisobutyric acid $(\boldsymbol{A I B})$.

NRP2945 has both neuroregenerative and anti-inflammatory effects in cultures of rat primary adult CNS neurons in vitro [15]. During neural regeneration experimentation with auto-immunity compromised MOG-EAE mice, NRP2945 is able to convert Th1/17 T-helper cell lymphocytes to Th2 T-helper cell lymphocytes, a feature that is crucial during regenerative processes of the CNS (Dr Claude Bernard, Monash University, unpublished results). Some epilepsy-prone rat strains like GEPR-9 have elevated numbers of peripheral mature Th1- T-helper cells (CD4 ${ }^{+} \mathrm{T}$ cells) when analysing splenocytes by flow cytometry [16]. Therefore, reduction and conversion of these pro-inflammatory $\mathrm{T}$ cells to $\mathrm{Th} 2$ helper $\mathrm{T}$ cells may provide anti-epileptogenic benefits to these rats. Also, in various experiments of neurodegeneration, targeted chemoattraction as well as upregulation of one cell cycle of committed neural stem cells followed by subsequent final differentiation (neuroregenerative activity of the NRP molecules) it has been shown that NRP2945 and its related analogues exert their effects via a novel heterodimeric chemokine receptor complex constellation consisting of CXCR4 and an undisclosed CCR subunit [17, 18]. NRP2945 has been shown to have $10^{6}$ times higher affinity to the monomeric subunit of CXCR4 than the endogenous ligand SDF-1 (also known as CXCL-12) which targets the homodimeric CXCR4 receptor complex. Whether this property of NRP2945 is relevant for seizures and epilepsy modulation is not currently known.

GAERS (Genetic Absence Epilepsy Rats from Strasbourg) are a well-validated polygenic rat model exhibiting spontaneous absence-like seizures [19]. The electrophysiological characteristics include synchronous and bilateral spike-and-wave discharge events which have a sudden onset and offset, apparently appearing simultaneously in both hemispheres. The 'spikes' occur at a frequency of around $7 \mathrm{~Hz}$, and oscillate across thalamo-cortical brain regions. The strain is commonly used to study the pathophysiology of epilepsy development [20], as well as to assess new anti-seizure treatments [21], with the pharmaco-responsivity resembling human absence seizures. Here we assessed whether NRP2945, previously shown to be able to fully prevent convulsive cortical seizures in the acute rat PTZ model [22], has efficacy against absence seizures in GAERS. We were motivated to study this model since NRP2945, and Neural Regeneration Peptides in 
general, have been shown to have neuro-reparative effects on the thalamus, and it is well established that thalamo-cortical circuits represent key brain structures known to be involved in absence seizures. Specifically, initially identified by phenotypic screening of thalamo-cortical brain slice co-cultures, NRPs provoke substantial regeneration of inhibitory thalamic neurons in ex vivo models even under oxidative stress conditions [17]. NRP2945 also displays significant anti-inflammatory activities, adding further motivation to study the GAERS model, since inflammation may play a role in the pathophysiology of absence epilepsy [23, 24].

\section{Methods}

\section{Animals}

We first performed a microdialysis study assessing the ability of NRP2945 to cross the bloodbrain barrier. For this, we used adult male Sprague-Dawley rats $(n=16)$, purchased from Harlan Laboratories, CA, USA. We then performed two epilepsy studies, using male Genetic Absence Epilepsy Rats from Strasbourg (GAERS; n=50) sourced from our GAERS-Melb colony [25]. All animals were housed under a 12-hour light-dark cycle, with food and water available ad libitum. Lighting for the epilepsy studies was on a $12 \mathrm{~h}$ light/dark cycle, with lights coming on at 7am. All animal experiments were conducted with prior approval from the Florey Animal Ethics Committee (15-096), or the Institutional Animal Care and Use Committee of Brains On-Line, LLC.

\section{Microdialysis probe surgery}

Rats were anesthetized using isoflurane $\left(2 \%, 800 \mathrm{~mL} / \mathrm{min} \mathrm{O}_{2}\right)$. Bupivacain/epinephrine was used for local analgesia and carprofen was used for peri-/post-operative analgesia. The animals were placed in a stereotaxic frame (Kopf instruments, USA). Animals were implanted with a microdialysis probe (Brainlink, Netherlands) with a regenerated cellulose membrane. Probes were inserted into the prefrontal cortex using stereotaxic guidance: $\mathrm{AP}=$ $+3.4 \mathrm{~mm}$ from bregma; lateral $=-0.8 \mathrm{~mm}$ from midline; ventral $=-5.0 \mathrm{~mm}$ from dura, with 4 mm exposed surface.

In the same surgical procedure, a catheter was placed into the jugular vein for drug administration. A $10 \mathrm{~cm}$ segment of silicone tubing (0.64 mm ID; $0.94 \mathrm{~mm}$ OD) was inserted into the right jugular vein. The catheter was then exteriorized through an incision on top of the head, where it was fitted onto a metal elbow. The catheter was kept patent by filling it with a $90 \%$ (v/v) glycerol solution containing $500 \mathrm{IE} / \mathrm{ml}$ heparin. The end of the venous 
catheter was fixed in position with dental acrylic cement and anchored to the skull with two stainless steel screws. After surgery animals were kept individually in cages.

\section{Microdialysis sampling}

The microdialysis experiments were conducted one day after surgery. The probes were connected with flexible PEEK tubing to a micro-perfusion pump (Harvard PHD 2000 Syringe pump, Holliston, MA or similar). Microdialysis probes were perfused with aCSF containing $147 \mathrm{mM} \mathrm{NaCl}, 3.0 \mathrm{mM} \mathrm{KCl}, 1.2 \mathrm{mM} \mathrm{CaCl}_{2}$ and $1.2 \mathrm{mM} \mathrm{MgCl}_{2}$, at a flow rate of 0.75 $\mu \mathrm{L} / \mathrm{min}$. Microdialysis samples were collected in 30 minute periods by an automated fraction collector (820 Microsampler, Univentor, Malta) into $300 \mu \mathrm{L}$ polypropylene mini-vials. After stabilization, one baseline sample was collected, and NRP2945 (1 mg/kg i.v.) was administered. Samples were collected for an additional 3 hours. All dialysate samples were stored at $-80{ }^{\circ} \mathrm{C}$ prior to analysis. Immediately after the completion of the experiment, the rats were humanely sacrificed.

\section{Analysis of NRP2945 in dialysates}

Concentrations of NRP2945 were determined by HPLC with tandem mass spectrometry (MS/MS) detection. 20 $\mu 1$ of the sample was injected into the LC system by an automated sample injector (CTC PAL, Switzerland). Chromatographic separation was performed on 100 x $2.0 \mathrm{~mm}$ Fusion-RP, Particle size $2.5 \mu \mathrm{m}$ (Phenomenex, Torrance, CA, USA). Components were separated using a linear gradient of acetonitrile $+0.1 \%$ formic acid (mobile phase $B$ ) in ultra-purified $\mathrm{H}_{2} \mathrm{O}+0.1 \%$ formic acid (Mobile phase A) (flow rate $0.2 \mathrm{ml} / \mathrm{min}$, delivered by an Agilent 1290 binary pump, Agilent, USA).

The flow of the LC was diverted to the waste for 2 minutes, after which it was switched to the MS for detection of NRP2945. MS analyses were performed using an API 5500 QTRAP system consisting of an API 5500 QTRAP detector and a Turbo V Ion Spray interface (Applied Biosystems, USA). The acquisitions were performed in positive ionization mode, with ion spray voltage set at $5.0 \mathrm{kV}$ with a probe temperature of $500{ }^{\circ} \mathrm{C}$. The instrument was operated in multiple-reaction-monitoring (MRM) mode. The collision gas (nitrogen) pressure was held at medium setting. The following mass transition were used for acquisition and quantitation: Q1 $=347(3+)$ that is equivalent to a triple-charged protonated NRP-2945-derived molecule, Q3 = $527.3(1+)$.

Data was quantified using the Analyst ${ }^{\mathrm{TM}}$ data system (Applied Biosystems, V1.5.2). The lower limit of detection using these specifications was $0.08 \mathrm{ng} / \mathrm{mL}$, corresponding to a 
free fraction concentration of $0.4 \mathrm{ng} / \mathrm{mL}$ (corrected for the recovery of the microdialysis probe as determined by an in-vitro recovery, data not shown).

\section{Electrode implantation surgery}

Extradural EEG recording electrodes were implanted to facilitate measurement of seizures as previously described [26]. Briefly, the animal was anaesthetised (2\% Isoflurane) and placed in a stereotaxic frame, when a midline incision was made on the scalp and six small burr holes made in the skull. These were positioned at $\pm 2 \mathrm{~mm}$ anterior/posterior, $\pm 2 \mathrm{~mm}$ lateral to bregma, and at $2 \mathrm{~mm}$ anterior, $\pm 2 \mathrm{~mm}$ lateral of lambda. Stainless steel electrode screws (Plastics One, Bioscientific, Australia) were gently implanted into the burr holes and the electrodes were stabilised with dental cement (Henry Schein Halas, Australia). Animals were individually housed following surgery, and for the remainder of the study.

\section{Acute treatment study}

The first EEG study conducted was an acute treatment paradigm, where the short-term effects of drug on seizures were assessed. For this study, animals received all drug treatments in a randomised order, with at least 3 days in between test days. The specific order for each animal was achieved using a random number generator. The 4 treatments were: $10 \mu \mathrm{g} / \mathrm{kg}$ NRP2945; 20 $\mathrm{g} / \mathrm{kg}$ NRP2945; 200mg/kg Valproaic Acid (VPA, Sigma); or vehicle (a solution consisting of $0.4 \%$ PEG (Sigma, St. Louis USA), $1 \%$ mannitol (Sigma) in 20mM sodium citrate (Sigma) ( $\mathrm{pH} 4.5)$, and 25mM D(+)-trehalose dihydrate (Sigma)). Doses were chosen based on a previous study showing efficacy against PTZ-induced seizures [22]. VPA was included as a best-in-class positive control treatment. NRP2945 was generously donated by CuroNZ. All injections were given sc in a volume of $\mathbf{2 0 0 \mu}$ l. On the day of testing, animals were individually housed in a quiet room under standard lighting conditions. Rats were gently held, and electrical cables (Plastics One) were connected to the implanted electrodes. EEG was acquired using Compumedics acquisition software (Compumedics, Australia) unfiltered and digitized at $256 \mathrm{~Hz}$. EEG was recorded for at least one hour prior to drug injection, and animals remained on the EEG undisturbed for 3 hours following injection. Injections were delivered before 11 am to avoid fluctuations of the identified NRP2945 target receptor subunit CXCR4 that has been described to show circadian rhythms in blood derived PBMCs and possibly CNS neurons [27].

\section{Chronic treatment study}


We compared the effects of 4 treatments in the current study, each having $n=10$ GAERS in the group. Animals were pseudo-randomised to treatment using random number generators corresponding to particular treatment after surgery for EEG electrodes. The treatment groups received $20 \mu \mathrm{g} / \mathrm{kg}$ every second day (e.s.d), $60 \mu \mathrm{g} / \mathrm{kg} / \mathrm{day}, 120 \mu \mathrm{g} / \mathrm{kg} / \mathrm{day}$, or vehicle. Animals receiving $20 \mu \mathrm{g} / \mathrm{kg}$ NRP2945 every second day (e.s.d) did so by subcutaneous injection of NRP2945 at 10am every other day. The other three treatment groups were briefly anaesthetised with isoflurane, and were implanted with an osmotic minipump (ALZET®) subcutaneously at the shoulder [28]. For some animals (n=5-6/group), treatment started one week following EEG electrode implantation, whereas for the rest, treatment was initiated at the same time as the EEG implants. The osmotic pumps we used had a capacity of $2 \mathrm{ml}$, and were designed to release drug continuously over 4 weeks. The concentrations required to achieve the desired dose (i.e., 0,60 or $120 \mu \mathrm{g} / \mathrm{kg} /$ day) were calculated on an average weight over the course of treatment of $260 \mathrm{~g} / \mathrm{rat}$. Animals were weighed weekly over the duration of the study, so the true dosage for each animal could be calculated. Four weeks after the implantation of the osmotic pump, the rats were briefly anaesthetised, and the pump removed. The pump was disassembled, and the residual volume of drug $(\sim 100 \mu l)$ calculated to ensure that the pumps were delivering the drug consistently. The vehicle used was as described above. We also undertook physico-chemical stability testing of NRP2945 at the relevant concentrations. Shelf-life analysis revealed fully preserved bioactivity for formulated NRP2945 assayed in validated neuroprotection/neurite outgrowth in vitro tests using oxidatively stressed cerebellar microexplant systems [17] when analysed after 4 week storage at $37^{0} \mathrm{C}$.

In this study, we monitored and assessed seizure frequency via EEG recordings several times over the course of the study, including prior to, and at 1 week and at 4 weeks following initiation of treatment, and then again at 10 days following the completion of treatment. Since seizure frequency increases over time in this model, we ensured that the respective postnatal ages (P110 for the acute study and P70 for the chronic study) of all animals were the same when compiling the data points. For EEG recordings, animals were housed and connected to the amplifiers as above. EEG was acquired continuously for 24 hours, beginning at midday, using Compumedics software (Compumedics, Australia). We assessed seizure frequency and duration from EEG traces recorded in an isolated three hour period $(12-3 \mathrm{am})$. We chose this period since this was consistently several hours after the animals had been handled to put the cables on, and this period was always free from external noises. 


\section{Seizure analysis}

EEG traces were exported from Profusion format, and codes for each trace blinded (NJ). The coded traces were then converted into edf format, and analysis of seizure frequency and duration was performed by a reviewer (GD) blinded to treatment and stage of experiment using Spike-and-Wave seizure detection program (SpikeWave Finder, Netherlands). This program automatically identifies spike-wave episodes, with each episode then visually verified. Inclusion criteria for seizures was a spike-wave discharge of amplitude more than two times baseline, a frequency of 7 to $9 \mathrm{~Hz}$, and a duration of longer than $1 \mathrm{sec}$. If two events occurred with less than $1 \mathrm{sec}$ in between the finish and end, they were counted as a single continuous event. After completion of seizure assessment in all traces, the code was broken by NJ and GD, and the final data tables compiled.

\section{Statistics}

Based on results from our previous studies assessing effects of drugs on seizures in GAERS (eg [21]), we calculated using the t-test that to detect a $30 \%$ decrease in seizure frequency, with the study parameters set at $\mathrm{p}=0.05$ (two-tailed) and beta $=0.20$, the estimated minimum number of animals required in each treatment group was 9. For all seizure data, these were first assessed for normality using the Shapiro-Wilk test. All group data passed this assessment ( $\mathbf{p}>0.05)$, and so we conducted subsequent parametric testing. For the acute treatment study, all post-treatment outcomes were calculated as change from baseline period, and then compared between groups using 1-way ANOVA with repeated measures. For the chronic treatment study, all post-treatment outcomes were compared between the groups using 2-way ANOVA with repeated measures, with Dunnett's post-hoc comparison test used when appropriate. We compared seizure outcomes prior to treatment in this study initiation using 1-way ANOVA. Statistical significance was defined as $\mathrm{p}<0.05$. Analyses were performed using Graphpad Prism 6.0 (La Jolla, CA, USA), and data represent mean \pm SEM.

\section{Results}

\section{Brain penetration of NRP2945}

After i.v. administration of NRP2945, we observed an immediate increase of unbound NRP2945 also characterised as the free fraction in the prefrontal cortex. With this treatment paradigm, NRP2945 reached a maximum free fraction concentration of $3 \pm 1 \mathrm{ng} / \mathrm{ml}$ at $30 \mathrm{~min}$ after administration, and then decreased. 90 minutes after administration of NRP2945, the 
free fraction concentration in brain decreased to levels which were below the detection level (i.e. $<0.08 \mathrm{ng} / \mathrm{ml}$ ) for all rats observed in this study. This data demonstrates blood-brain permeability of our test compound with a bioavailability of approximately $0.04-0.05 \%$. Because picomolar and even subpicomolar concentrations of NRP2945 are sufficient to exert anti-convulsant activity, the low bioavailability is not detrimental to the drug candidate's action. It is known that other anti-convulsive peptides that act via G-protein coupled receptors, like glycosylated neurotensin analogues also possess subpicomolar efficacy when administered via the ICV route [29].

\section{Effects of treatment on seizures - acute study}

All animals exhibited consistent typical Spike-and-Wave discharge seizures typical of GAERS (Figure 2A), and this was the only seizure type we observed. In the baseline periods, animals experienced $31.6 \pm 4.2$ seizures/hr. All animals tolerated all treatments well, with no adverse events identified. When comparing the effects of acute drug treatment on seizures, we found a significant reduction in seizure frequency observed with the test compounds (ANOVA F=4.55, p=0.013; Figure 2B). This was most pronounced in animals treated with $20 \mu \mathrm{g} / \mathrm{kg}$ NRP2945 (post-hoc comparison $\mathrm{p}<0.01$ ), which was more effective at reducing seizures than the positive control, 200mg/kg VPA $(\mathrm{p}<0.05)$. Anti-seizure effects were also evident when assessing the $\%$ time in seizure $(\mathrm{F}=4.1, \mathrm{p}=0.02$; Figure $2 \mathrm{C})$. This was also highly significant for animals treated with NRP2945 compared with controls $(\mathrm{p}<0.01)$. Seizure duration did not change with treatment (ANOVA F=0.5, $\mathrm{p}=0.61$, not shown).

\section{Monitoring of drug toxicity and effectiveness of the chronic dosing schedules}

In the chronic epilepsy study, all animals tolerated the drug treatments and surgical interventions very well. The weight gains over the course of the study were consistent, and did not differ between the treatment groups $\left(\mathrm{F}_{(3,36)}=0.98 ; \mathrm{p}=0.4\right.$; Figure $\left.3 \mathrm{~A}\right)$ implying that NRP2945 has no detrimental weight effects on GAERS rats. We observed no adverse motor system or sensory system related incidents (i.e, ataxia, increased nociception, or irritability) associated with the treatments.

The continuous osmotic pump delivery system is designed to release a consistent amount of drug each day for the life of the pump, meaning that each animal within each drug candidate concentration group receives the same amount of drug per day over the course of the experiment. As the animal ages, they put on weight, and so with a consistent delivery mechanism, the dose per weight will reduce over time. We calculated the individual dosing 
which each animal received over the course of the experiment. As expected, while the calculated dose received consistently reduced over time for all rats which had the pumps implanted, over the 4 week treatment period, the average dose over the course of the study was similar to the target dose: animals predicted to receive $60 \mu \mathrm{g} / \mathrm{kg} /$ day over the course of the study received $62.8 \pm 1.3 \mu \mathrm{g} / \mathrm{kg} /$ day, whereas animals predicted to receive $120 \mu \mathrm{g} / \mathrm{kg} / \mathrm{day}$ received $119.7 \pm 1.9 \mu \mathrm{g} / \mathrm{kg} / \mathrm{day}$, validating the use of these pumps (Figure 3B). For these calculations, we make the assumption that the pumps deliver drug at a constant flow rate over the course of the experiment.

\section{Effects of treatment on seizures - chronic study}

In one cohort of animals ( $\mathrm{n}=5-6 /$ group), we measured seizure frequency prior to initiation of drug treatment. After these animals were randomised to treatment, we retrospectively compared treatment groups for epilepsy severity. As expected, there were no significant differences between animals that were allocated to different treatment groups (seizure frequency: vehicle treated group $=17.3 \pm 3.0$ seizures $/ \mathrm{hr} ; 20 \mu \mathrm{g} / \mathrm{kg}$ e.s.d $=21.2 \pm 1.9$; $60 \mu \mathrm{g} / \mathrm{kg} / \mathrm{day}=22.9 \pm 1.5 ; 120 \mu \mathrm{g} / \mathrm{kg} / \mathrm{day}=20.7 \pm 4.1: \mathrm{F}_{(3,17)}=0.7, \mathrm{p}=0.6 ;$ seizure duration: vehicle $=7.0 \pm 0.4 \mathrm{sec} ; 20 \mu \mathrm{g} / \mathrm{kg}$ e.s.d $=7.0 \pm 0.7 ; 60 \mu \mathrm{g} / \mathrm{kg} / \mathrm{day}=7.9 \pm 0.5 ; 120 \mu \mathrm{g} / \mathrm{kg} / \mathrm{day}=$ $\left.7.8 \pm 0.5: F_{(3,17)}=0.7, p=0.6 ; F_{(3,17)}=0.7, p=0.6\right)$.

When comparing the numbers of seizures experienced by GAERS in the different treatment groups after treatment had started, we found significant differences $\left(F_{(3,36)}=7.55\right.$; $\mathrm{p}=0.0006$; Figure 4A). GAERS treated with $120 \mu \mathrm{g} / \mathrm{kg} / \mathrm{day} \quad(\mathrm{p}<0.001)$ and $20 \mu \mathrm{g} / \mathrm{kg}$ subcutaneous bolus delivered every other day $(\mathrm{p}<0.01)$ exhibited significantly fewer seizures than vehicle-treated GAERS. Animals treated with $60 \mu \mathrm{g} / \mathrm{kg} /$ day also experienced fewer seizures than controls, but this did not reach statistical significance. What was most encouraging was that the effects of 4 weeks of treatment were sustained until at least 10 days after the drug had been removed from the system, with substantially fewer seizures being experienced by the rats in all three treatment groups at the final measurement stage $(20 \mu \mathrm{g} / \mathrm{kg}$ e.s.d - 43\% reduction; $60 \mu \mathrm{g} / \mathrm{kg} / \mathrm{day}$ - 30\% reduction; $120 \mu \mathrm{g} / \mathrm{kg} / \mathrm{day}$ - $34 \%$ reduction), compared to vehicle-treated GAERS. We did not observe any effects of treatment on the average of duration of seizure events which occurred in the treatment groups $\left(\mathrm{F}_{(3,36)}=0.36\right.$; $\mathrm{p}=0.78$; Figure 4B). 


\section{Discussion}

We demonstrate here pronounced anti-seizure effects in the GAERS model of absence epilepsy exerted by neural regeneration peptide (NRP) 2945, a small peptide with proven anti-inflammatory and neuroregenerative properties. The rapid acute anti-epileptic effect of NRP2945 already seen between 0-30 min after only one bolus subcutaneous injection implies that the $\mathrm{G}_{\mathrm{i}}$ part of the CXCR4 related G-protein is quickly activated. This would lead to increased Egr1 transcription factor interaction at respective consensus binding sequences of the glutamate decarboxylase (GAD) promoter, provoking gene upregulation and subsequent de novo GABA production within minutes throughout thalamo-cortical circuits and other regions of the brain [30]. This biological action has been shown for NRP2945 by immunocytochemical analysis of GABA in various brain regions of rats treated acutely with PTZ [22]. That study also showed increased protein expression for $\mathrm{GABA}_{\mathrm{A}}$ receptor subunits alpha and beta that are constituents of the synaptic form of the $\mathrm{GABA}_{\mathrm{A}}$ receptor. This biological action of NRP2945 has great advantages to GABAergic active AEDs like benzodiazepines because there is no allosteric regulation on the $\mathrm{GABA}_{\mathrm{A}}$ receptor level. In contrast, GABA production/secretion is upregulated together with the translational products of the $\mathrm{GABA}_{\mathrm{A}}$ receptor. This could be indeed beneficial during status epilepticus where $\mathrm{GABA}_{\mathrm{A}}$ receptors are internalized and therefore are unreachable by small molecule AEDs. All measured pharmacodynamics effects of NRP2945 were achieved without any signs of toxicity, and using a far lower dose (70000x less on a molar basis) than sodium valproate.

Most impressive was that the effects of chronic treatment were sustained for at least 10 days following conclusion of the treatment period, indicative of potent disease-modifying effects of NRP. This compound has also been shown to be efficacious against acute PTZ-induced focal seizures and alleviating neuronal damage [22], and therefore presents a potential novel human anti-seizure drug candidate which possesses broad efficacy against a range of seizure types.

An alternate possible mechanism of action of NRP2945 in regard to its diseasemodifying effect after cessation of treatment may be related to its anti-inflammatory actions, like a predominance of peripheral Th2 T-lymphocytes especially after induced TCR responses mediated by anti-CD3/CD28 antibody induction in vitro protocols. Inflammatory processes are activated in several different models of epilepsy, primarily in focal lesion models where neuropathology, including gliosis, is common [5]. However, increasing evidence suggests an influence of inflammatory mediators in absence epilepsy: bacterial infection with lipopolysaccharide, which triggers an inflammatory response, increases the 
frequency of absence seizures in both the GAERS and WAG/Rij models of genetic absence epilepsy $[23,24]$. Also, upregulation of reactive astrocytes and interleukin-1 $\beta$ are observed in the somatosensory cortex in adult GAERS [31]. Furthermore, administration of inflammatory cytokines IL-1 $\beta$ and TNF- $\alpha$ increase absence seizures [32], providing direct evidence that these inflammatory mediators enhance absence seizure frequency. NRP is a potent stimulator of neuronal growth and differentiation, and these effects are likely driven by activation of the chemokine receptor CXCR4 [17] as has been shown in auto-immunity models as well as in CXCR4 gene expression analysis of oxidatively stressed human neural stem cells (unpublished data). CXCR4 is a receptor with strong links to inflammatory processes [33, 34]. This presents as a strong candidate mechanism through which NRP2945 may influence seizure expression in GAERS.

We show here also that NRP2945 successfully enters the brain in detectable levels using microdialysis and LC-MS. The acute dosing used in the microdialysis study was $1 \mathrm{mg} / \mathrm{kg}$ (iv), with this dose resulted in a free fraction in the brain dialysate of $\sim 3 \mathrm{ng} / \mathrm{ml}$ NRP2945. In contrast, a much lower dose $20 \mu \mathrm{g} / \mathrm{kg}$ (sc) was efficacious in the epilepsy

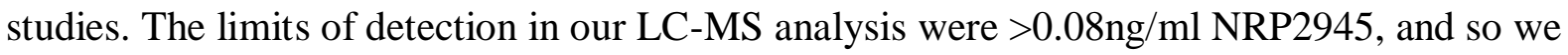
estimated that our assay would not be sensitive enough to detect the dose used in the epilepsy study, hence why we altered the dose of drug injected, and the method of delivery for the microdialysis study. Extrapolating the microdialysis data, a dose of $20 \mathrm{ug} / \mathrm{kg}$ sc would be expected to result in brain levels of $\sim 60 \mathrm{pg} / \mathrm{ml}(\sim 60 \mathrm{nM})$. This concentration is far above the EC50 value for neuroprotection of $10-100 \mathrm{fM}$ in a cell toxicity assay (personal communication with F. Sieg), and suggests that the dose delivered in the epilepsy study would be sufficient to be functionally active in the brain. In addition to glial cells in the brain, CXCR4 receptors are expressed on cholinergic and dopaminergic neurons [35]. These neurotransmitter systems are recognised to influence absence seizures [36], and so the antiseizure mechanism of action of NRP2945 may be related to direct changes in excitability of neurons.

Our treatment study protocols attempted to follow as many guidelines recommended by an NINDS-driven discussion regarding quality and transparency of study design and methodology in preclinical research [37]. These included: randomisation of treatment, blinded review of outcome data, rigorous sample size calculations (see methods for further details). Other aspects were not able to be achieved, including blinding of treatments during the chronic experiments (since only one treatment group required repeated injections). Also, our animals were 'pseudo-randomised' into treatment groups meaning that if a particular 
group had 10 animals enrolled, any subsequent animal allocated to this treatment group was randomly chosen to join another that still required participants. For the acute study, we used a randomised treatment paradigm with repeated testing. The primary advantages of this are that, because each subject receives each dose of drug, this animal essentially acts as its own control, which increases the power of the study, and consequently reduces the number of subjects required. The down-side is that there may be sustained effects of the treatments which influence subsequent testing. However, we do not believe this can account for our results. Because the treatments were randomised, any lingering effects caused by the repeated exposure to NRP would lead to increased variability within each treatment group, rather than a systematic bias.

One limitation worth mentioning is the lack of appropriate control group for animals receiving $20 \mu \mathrm{g} / \mathrm{kg}$ e.s.d in the chronic study. The most appropriate controls would have been additional animals which received injections of the vehicle rather than vehicle delivered via osmotic pump, or alternatively animals injected with vehicle + scrambled peptide. This would therefore have controlled for the stress of the injections, and the animal handling associated with the procedure, as well as removed the anaesthesia experienced as part of the implant and explant of the osmotic pump. Our protocol required all animals to be handled several times per week, for animal monitoring purposes and also to connect and disconnect them from the EEG cables. In addition, the injections were delivered subcutaneously in a very small volume $(\sim 200 \mu \mathrm{l})$ by a senior scientist (GD) with extensive experience in this procedure 14 hours prior to assessment of seizures, long after any acute stress response associated with the injection procedure had resolved.

In addition, we did not incorporate a 'positive control' for the chronic study, which makes comparison with current best-in-class treatments for absence seizures difficult. However, we have previously studied the effects of chronic ethosuximide treatment in GAERS, demonstrating a $\sim 70 \%$ reduction in seizure frequency while treatment persists, slightly greater than that observed here ( $40 \%$ reduction). Comparing the post-treatment effects of these treatments, here we demonstrate animals previously treated with NRP2945 experience $\sim 45 \%$ fewer seizures one week after cessation of treatment, compared with $\sim 30 \%$ reduction in seizures following removal of ethosuximide. Although the timing, duration and route of treatment are different in these studies, comparison of the data suggests that, conservatively, NRP2945 is similarly efficacious during treatment, but has more potent disease-modifying effects than ethosuximide in GAERS. 
In summary, here we demonstrate clear and sustained anti-seizure effects of long-term treatment with NRP2945 in an animal model of absence epilepsy. This drug effectively crosses the blood-brain barrier, and is devoid of any side effects. The doses required for efficacy are many orders of magnitude lower than current treatments. We are initiating early phase clinical trials, which, if successful, will result in the first human anti-epileptic drug that has no known off-target effects (including no effects on a kinase advisor panel and cytochrome P450 enzyme systems - personal communication) and also no known adverse toxicity effects and therefore presents as a potential safe and efficacious treatment option for patients.

\section{Acknowledgements:}

We acknowledge the generous financial support from CURONZ for this study. NJ is supported by an ARC Future Fellowship.

\section{Figure legends}

Figure 1: NRP2945 crosses the blood brain barrier, and is detectable in the prefrontal cortex of rats up to 60 minutes following i.v. administration using LC/MS. Data represent mean \pm S.E.M; $n=3$.

Figure 2: Effects of acute treatment with NRP2945 on absence seizures in GAERS. An example of a spike-wave discharge event recorded from one animal (A). Significant reductions in seizure frequency (B) and \% time in seizure (C) were observed following treatment with NRP $294520 \mu \mathrm{g} / \mathrm{kg}$ and 200mg/kg VPA, compared with vehicle treatment. Data represent mean \pm S.E.M; $n=9$. $* \mathrm{p}<0.05 ; * * \mathrm{p}<0.01$, compared to vehicle.

Figure 3: Chronic dosing schedule and toxicity of NRP2945. Chronic exposure to NRP2945 does not influence weight gain over time (A) without any significant differences in weight observed between treatment groups. Over time, the dose of drug received reduces as weight increases for both 60 and $120 \mu \mathrm{g} / \mathrm{kg} /$ day groups (B). The average doses received over the treatment period were very similar to the expected doses. Data represent mean \pm S.E.M; $\mathrm{n}=10 /$ group. 
Figure 4: Effects of chronic treatment with NRP2945 on absence seizures in GAERS. The number of seizures recorded was significantly fewer in animals treated with $20 \mu \mathrm{g} / \mathrm{kg}$ e.s.d. and $120 \mu \mathrm{g} / \mathrm{kg} /$ day compared to vehicle treatment over the course of the experiment (A). This was evident during the treatment phase, and also after treatment had been completed. No differences were observed in the average duration of seizures in the treatment groups (B). Data represent mean \pm S.E.M; $n=10$ /group. $* * p<0.01$; *** $p<0.001$, compared to vehicle.

\section{References:}

1. Shorvon SD (2009) Drug treatment of epilepsy in the century of the ILAE: the second 50 years, 1959-2009. Epilepsia 50 Suppl 3:93-130

2. Kwan P, Brodie MJ (2000) Early identification of refractory epilepsy. The New England journal of medicine 342:314-319

3. Frasca A, Aalbers M, Frigerio F, Fiordaliso F, Salio M, Gobbi M, Cagnotto A, Gardoni F, Battaglia GS, Hoogland G, Di Luca M, Vezzani A (2011) Misplaced NMDA receptors in epileptogenesis contribute to excitotoxicity. Neurobiol Dis 43:507-515

4. Bonora E, Graziano C, Minopoli F, Bacchelli E, Magini P, Diquigiovanni C, Lomartire S, Bianco F, Vargiolu M, Parchi P, Marasco E, Mantovani V, Rampoldi L, Trudu M, Parmeggiani A, Battaglia A, Mazzone L, Tortora G, Imgsac, Maestrini E, Seri M, Romeo G (2014) Maternally inherited genetic variants of CADPS2 are present in autism spectrum disorders and intellectual disability patients. EMBO Mol Med 6:795-809

5. Vezzani A, French J, Bartfai T, Baram TZ (2011) The role of inflammation in epilepsy. Nat Rev Neurol 7:31-40

6. Choi J, Nordli DR, Jr., Alden TD, DiPatri A, Jr., Laux L, Kelley K, Rosenow J, Schuele SU, Rajaram V, Koh S (2009) Cellular injury and neuroinflammation in children with chronic intractable epilepsy. J Neuroinflammation 6:38

7. Fabene PF, Navarro Mora G, Martinello M, Rossi B, Merigo F, Ottoboni L, Bach S, Angiari S, Benati D, Chakir A, Zanetti L, Schio F, Osculati A, Marzola P, Nicolato E, Homeister JW, Xia L, Lowe JB, McEver RP, Osculati F, Sbarbati A, Butcher EC, Constantin G (2008) A role for leukocyte-endothelial adhesion mechanisms in epilepsy. Nat Med 14:1377-1383 
8. Fabene PF, Bramanti P, Constantin G (2010) The emerging role for chemokines in epilepsy. J Neuroimmunol 224:22-27

9. Bien CG, Urbach H, Schramm J, Soeder BM, Becker AJ, Voltz R, Vincent A, Elger CE (2007) Limbic encephalitis as a precipitating event in adult-onset temporal lobe epilepsy. Neurology 69:1236-1244

10. Varadkar S, Bien CG, Kruse CA, Jensen FE, Bauer J, Pardo CA, Vincent A, Mathern GW, Cross JH (2014) Rasmussen's encephalitis: clinical features, pathobiology, and treatment advances. Lancet Neurol 13:195-205

11. Maroso M, Balosso S, Ravizza T, Liu J, Aronica E, Iyer AM, Rossetti C, Molteni M, Casalgrandi M, Manfredi AA, Bianchi ME, Vezzani A (2010) Toll-like receptor 4 and high-mobility group box-1 are involved in ictogenesis and can be targeted to reduce seizures. Nat Med 16:413-419

12. Marchi N, Fan Q, Ghosh C, Fazio V, Bertolini F, Betto G, Batra A, Carlton E, Najm I, Granata T, Janigro D (2009) Antagonism of peripheral inflammation reduces the severity of status epilepticus. Neurobiol Dis 33:171-181

13. Dedeurwaerdere S, Friedman A, Fabene PF, Mazarati A, Murashima YL, Vezzani A, Baram TZ (2012) Finding a better drug for epilepsy: antiinflammatory targets. Epilepsia 53:1113-1118

14. Sadakata T, Mizoguchi A, Sato Y, Katoh-Semba R, Fukuda M, Mikoshiba K, Furuichi T (2004) The secretory granule-associated protein CAPS2 regulates neurotrophin release and cell survival. J Neurosci 24:43-52

15. Sieg F, Antonic A (2007) In vitro strategies to enable the establishment of a functional CNS network. In: Sogos V, Diana A (eds) Alternative Strategies in Neuroregeneration and Neurogenesis Research signpost edition pp 27-58

16. De Sarro G, Liberto MC, Berlinghieri MC, Foca A, Aragona M, Cavaliere R, Gulletta E (1996) Impairment of immunological functions in genetically epilepsy-prone rats. Gen Pharmacol 27:643-646

17. Gorba T, Bradoo P, Antonic A, Marvin K, Liu DX, Lobie PE, Reymann KG, Gluckman PD, Sieg F (2006) Neural regeneration protein is a novel chemoattractive and neuronal survival-promoting factor. Exp Cell Res 312:3060-3074

18. Singh AT, Keelan JA, Sieg F (2010) Regulation of trophoblast migration and survival by a novel neural regeneration peptide. Reprod Biomed Online 21:237-244

19. Marescaux C, Vergnes M, Depaulis A (1992) Genetic absence epilepsy in rats from Strasbourg--a review. J Neural Transm Suppl 35:37-69 
20. Jones NC, O'Brien TJ, Powell KL (2011) Morphometric changes and molecular mechanisms in rat models of idiopathic generalized epilepsy with absence seizures. Neurosci Lett 497:185-193

21. Tringham E, Powell KL, Cain SM, Kuplast K, Mezeyova J, Weerapura M, Eduljee C, Jiang X, Smith P, Morrison JL, Jones NC, Braine E, Rind G, Fee-Maki M, Parker D, Pajouhesh H, Parmar M, O'Brien TJ, Snutch TP (2012) T-type calcium channel blockers that attenuate thalamic burst firing and suppress absence seizures. Sci Trans1 Med 4:121ra119

22. Sajadian A, Esteghamat S, Karimzadeh F, Eshaghabadi A, Sieg F, Speckmann EJ, Meuth S, Seidenbecher T, Budde T, Gorji A (2015) Anticonvulsant effect of neural regeneration peptide 2945 on pentylenetetrazol-induced seizures in rats. Neuropeptides 49:15-23

23. Kovacs Z, Dobolyi A, Juhasz G, Kekesi KA (2014) Lipopolysaccharide induced increase in seizure activity in two animal models of absence epilepsy WAG/Rij and GAERS rats and Long Evans rats. Brain research bulletin 104:7-18

24. Russo E, Andreozzi F, Iuliano R, Dattilo V, Procopio T, Fiume G, Mimmi S, Perrotti N, Citraro R, Sesti G, Constanti A, De Sarro G (2014) Early molecular and behavioral response to lipopolysaccharide in the WAG/Rij rat model of absence epilepsy and depressive-like behavior, involves interplay between AMPK, AKT/mTOR pathways and neuroinflammatory cytokine release. Brain Behav Immun 42:157-168

25. Powell KL, Tang H, Ng C, Guillemain I, Dieuset G, Dezsi G, Carcak N, Onat F, Martin B, O'Brien TJ, Depaulis A, Jones NC (2014) Seizure expression, behavior, and brain morphology differences in colonies of Genetic Absence Epilepsy Rats from Strasbourg. Epilepsia 55:1959-1968

26. Jones NC, Salzberg MR, Kumar G, Couper A, Morris MJ, O'Brien TJ (2008) Elevated anxiety and depressive-like behavior in a rat model of genetic generalized epilepsy suggesting common causation. Exp Neurol 209:254-260

27. Cermakian N, Westfall S, Kiessling S (2014) Circadian clocks and inflammation: reciprocal regulation and shared mediators. Arch Immunol Ther Exp (Warsz) 62:303318

28. Liu SJ, Zheng P, Wright DK, Dezsi G, Braine E, Nguyen T, Corcoran NM, Johnston LA, Hovens CM, Mayo JN, Hudson M, Shultz SR, Jones NC, O'Brien TJ (2016) Sodium selenate retards epileptogenesis in acquired epilepsy models reversing 
changes in protein phosphatase 2A and hyperphosphorylated tau. Brain 139:19191938

29. Lee HK, Zhang L, Smith MD, White HS, Bulaj G (2009) Glycosylated neurotensin analogues exhibit sub-picomolar anticonvulsant potency in a pharmacoresistant model of epilepsy. ChemMedChem 4:400-405

30. Luo Y, Lathia J, Mughal M, Mattson MP (2008) SDF1alpha/CXCR4 signaling, via ERKs and the transcription factor Egr1, induces expression of a 67-kDa form of glutamic acid decarboxylase in embryonic hippocampal neurons. The Journal of biological chemistry 283:24789-24800

31. Akin D, Ravizza T, Maroso M, Carcak N, Eryigit T, Vanzulli I, Aker RG, Vezzani A, Onat FY (2011) IL-1beta is induced in reactive astrocytes in the somatosensory cortex of rats with genetic absence epilepsy at the onset of spike-and-wave discharges, and contributes to their occurrence. Neurobiol Dis 44:259-269

32. van Luijtelaar G, Lyashenko S, Vastyanov R, Verbeek G, Oleinik A, van Rijn C, Volokhova G, Shandra A, Coenen A, Godlevsky L (2012) Cytokines and Absence Seizures in a Genetic Rat Model. Neurophysiology 43:478-486

33. Kucia M, Jankowski K, Reca R, Wysoczynski M, Bandura L, Allendorf DJ, Zhang J, Ratajczak J, Ratajczak MZ (2004) CXCR4-SDF-1 signalling, locomotion, chemotaxis and adhesion. J Mol Histol 35:233-245

34. Charo IF, Ransohoff RM (2006) The many roles of chemokines and chemokine receptors in inflammation. The New England journal of medicine 354:610-621

35. Banisadr G, Fontanges P, Haour F, Kitabgi P, Rostene W, Melik Parsadaniantz S (2002) Neuroanatomical distribution of CXCR4 in adult rat brain and its localization in cholinergic and dopaminergic neurons. Eur J Neurosci 16:1661-1671

36. Danober L, Deransart C, Depaulis A, Vergnes M, Marescaux C (1998) Pathophysiological mechanisms of genetic absence epilepsy in the rat. Progress in neurobiology 55:27-57

37. Landis SC, Amara SG, Asadullah K, Austin CP, Blumenstein R, Bradley EW, Crystal RG, Darnell RB, Ferrante RJ, Fillit H, Finkelstein R, Fisher M, Gendelman HE, Golub RM, Goudreau JL, Gross RA, Gubitz AK, Hesterlee SE, Howells DW, Huguenard J, Kelner K, Koroshetz W, Krainc D, Lazic SE, Levine MS, Macleod MR, McCall JM, Moxley RT, 3rd, Narasimhan K, Noble LJ, Perrin S, Porter JD, Steward O, Unger E, Utz U, Silberberg SD (2012) A call for transparent reporting to optimize the predictive value of preclinical research. Nature 490:187-191 


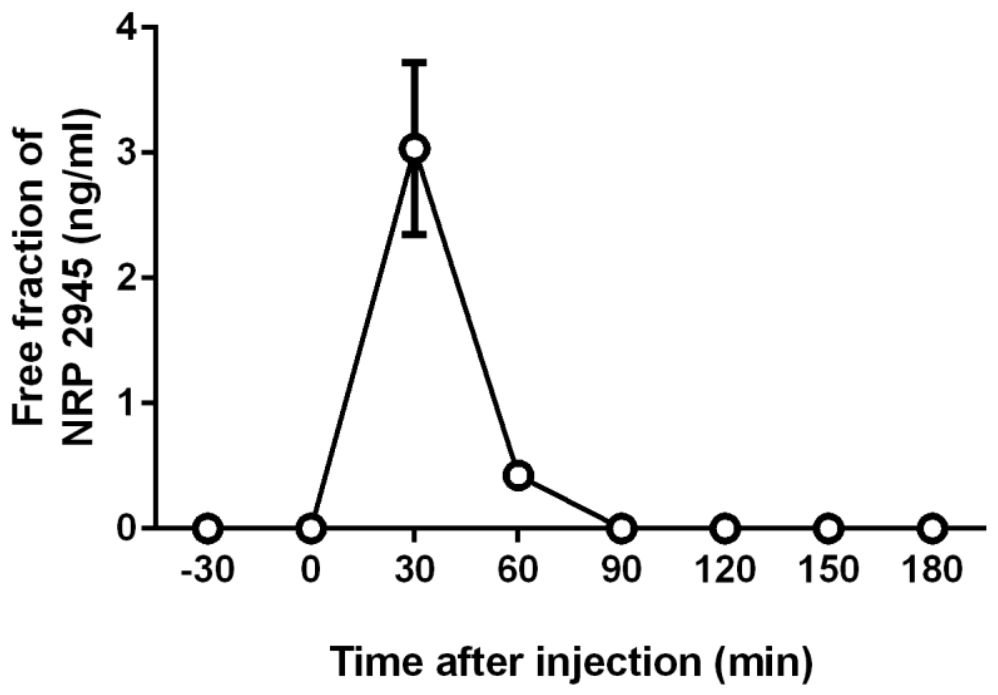



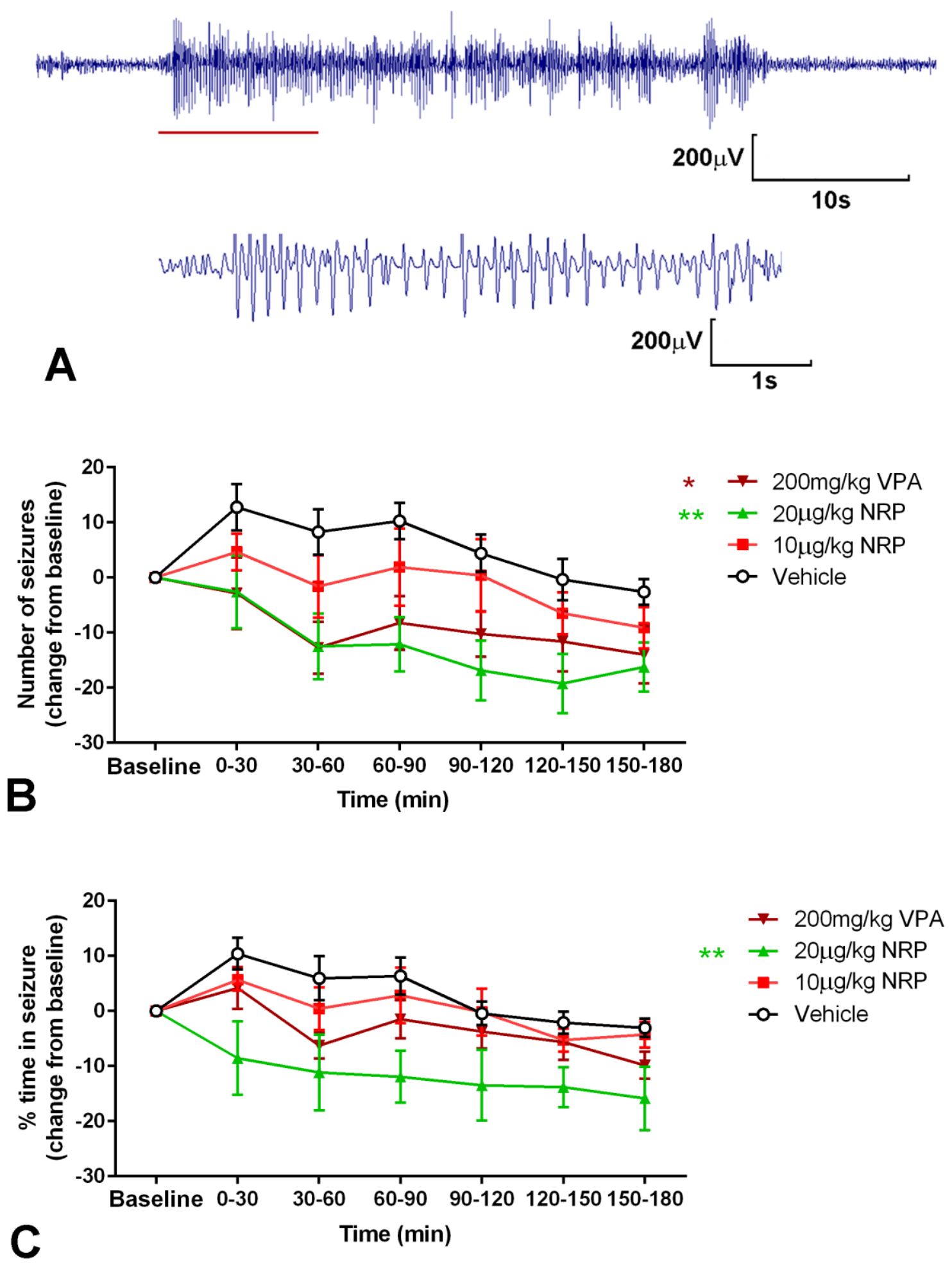


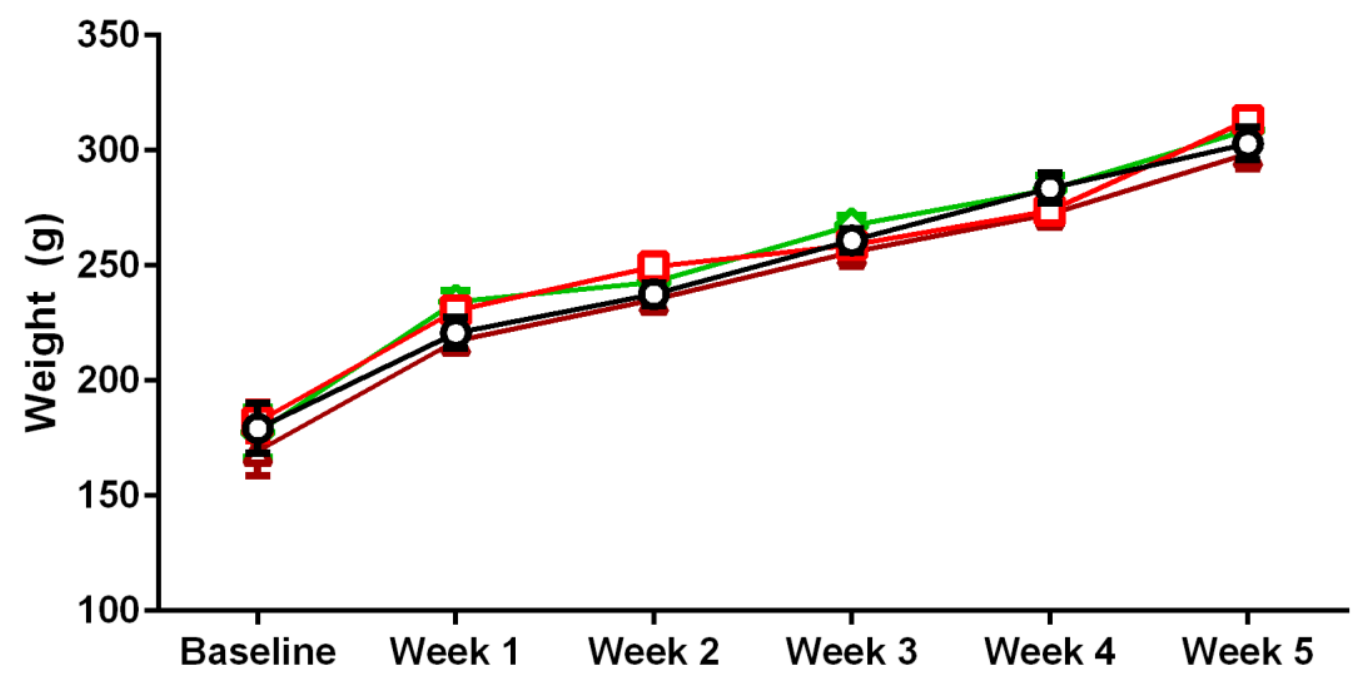

A

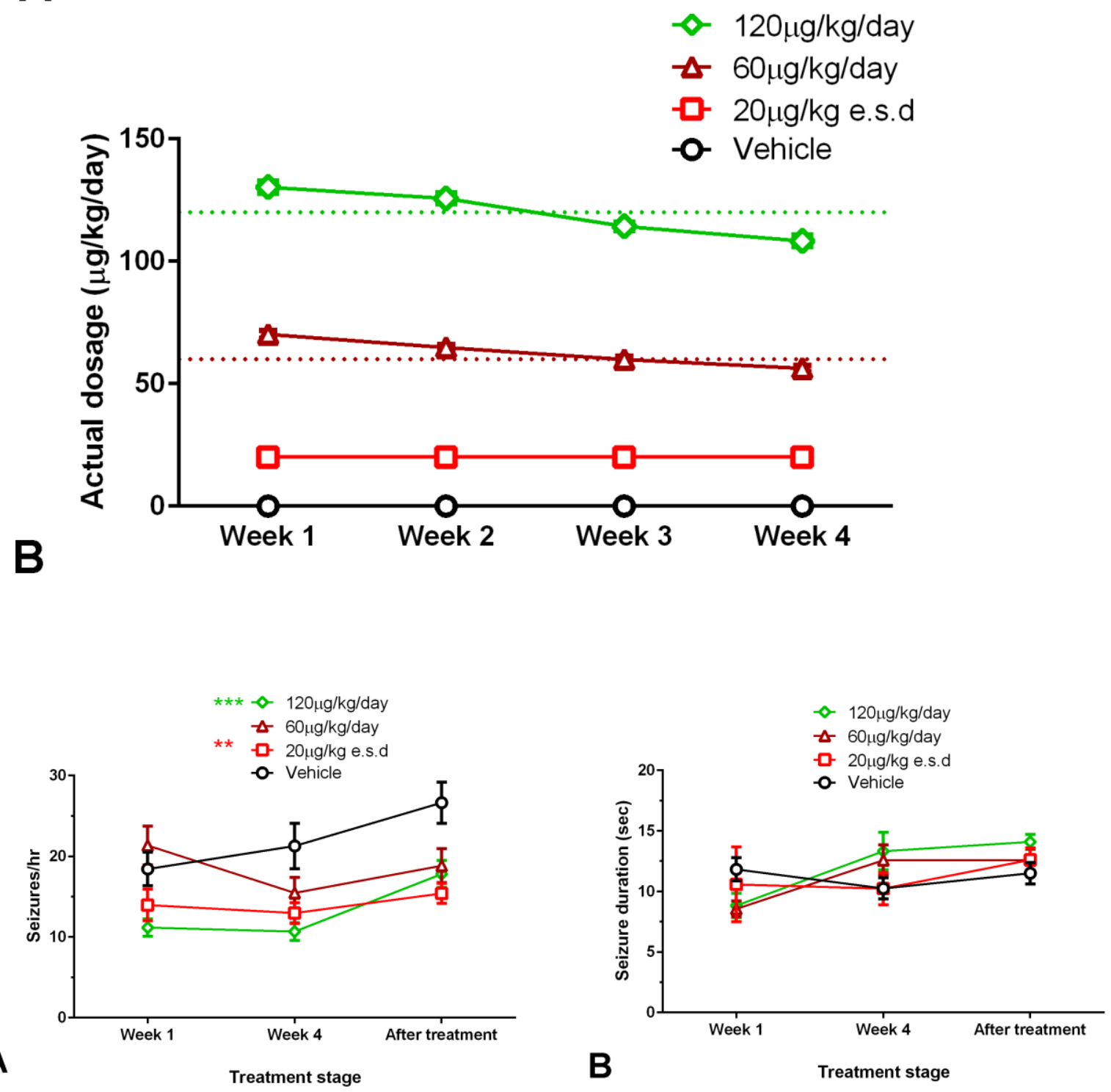

